\title{
The beginning of the end of the increase in mortality from carcinoma of the lung
}

\author{
V. H. SPR I N G E T T \\ From the Department of Social Medicine, the Medical School, Birmingham, \\ and the Birmingham Chest Clinic
}

The mortality from carcinoma of most sites increases progressively with age, at least up to age 80 years. However, since about 1920, mortality from carcinoma of the lung in males has been an exception to this general rule in that the mortality rates rise to a maximum, usually at age 60-64 or 65-69 years, and then fall in older age-groups (Springett, 1950a). Figure 1 demonstrates this for the quinquennium $1956-60$; the curve for carci-

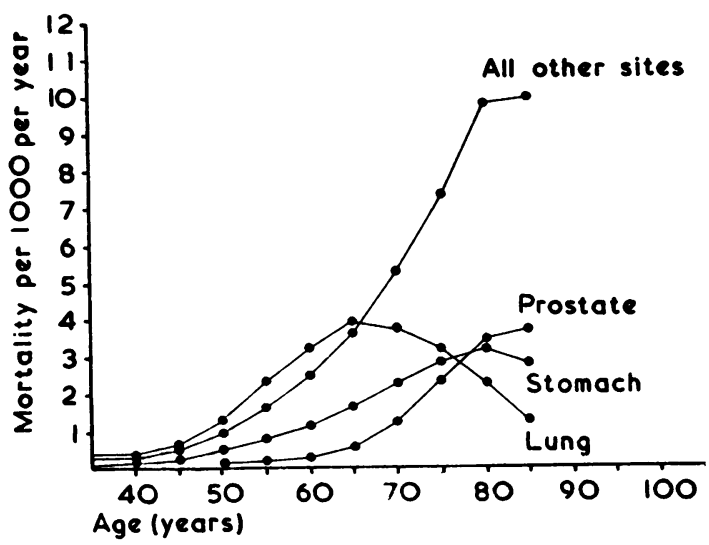

FIG. 1. Mortality rates from carcinoma of stated sites for age-groups of males, England and Wales, 1956-60. noma of the lung, with a peak in this quinquennium at age 65-69 years, contrasts with the steadily rising curves of mortality from carcinoma of the stomach, prostate, and all other sites combined.

The curve for mortality from carcinoma of the lung in Fig. 1 is obtained from Table $I$ by reading horizontally along the last row but one ; reading along the rows of such a table is the way in which age distributions of mortality are customarily studied.

However, it is also valid to obtain an age distribution of mortality from such a table by reading it diagonally from top left towards bottom right, provided that the time intervals are the same vertically and horizontally, in this case five years for each. If this is done, the mortality experience of the survivors of a group of persons born within a limited period of time is followed throughout their lifetime, and to such a group the term 'cohort' has been applied. Case $(1956 \mathrm{a}, \mathrm{b})$ has demonstrated mortality rates from carcinoma of the lung very fully in this way and has shown that for 'cohorts' there is a steady increase of mortality with age, as is usual for carcinoma of most sites. A similar phenomenon in the death rates for carcinoma of the lung in other countries has been shown by Korteweg (1951, 1953), Clemmesen, Nielsen, and Jensen (1953), Levin (1953), Dorn

TAB LE I

MORTALITY RATES PER 1,000 MALES PER YEAR FROM CANCER OF THE LUNG AND PLEURA IN FIVE-YEAR AGEGROUPS FOR QUINQUENNIA 1921-25 TO 1956-60, AND THE YEAR 1963 IN ENGLAND AND WALES

\begin{tabular}{|c|c|c|c|c|c|c|c|c|c|c|c|c|}
\hline & \multicolumn{12}{|c|}{ Age (yrs.) } \\
\hline & 30 & 35 & $40-$ & 45 & $50-$ & 55- & $60-$ & $65-$ & $70-$ & $75-$ & $80-$ & $85+$ \\
\hline $\begin{array}{l}1921-25 \\
1926-30 \\
1931-35 \\
1936-40 \\
1941-45 \\
1946-50 \\
1951-55 \\
1956-60 \\
1963\end{array}$ & $\begin{array}{l}0.008 \\
0.011 \\
0.020 \\
0.030 \\
0.034 \\
0.036 \\
0.035 \\
0.035 \\
0.036\end{array}$ & $\begin{array}{l}0.018 \\
0.022 \\
0.054 \\
0.068 \\
0.081 \\
0.094 \\
0.098 \\
0.093 \\
0.085\end{array}$ & $\begin{array}{l}0.027 \\
0.052 \\
0.087 \\
0.149 \\
0.191 \\
0.236 \\
0.248 \\
0.251 \\
0.205\end{array}$ & $\begin{array}{l}0.044 \\
0.076 \\
0.186 \\
0.274 \\
0.384 \\
0.544 \\
0.579 \\
0.590 \\
0.576\end{array}$ & $\begin{array}{l}0.066 \\
0.112 \\
0.256 \\
0.431 \\
0.597 \\
0.954 \\
1.224 \\
1.248 \\
1.200\end{array}$ & $\begin{array}{l}0.087 \\
0.148 \\
0.348 \\
0.586 \\
0.883 \\
1 \cdot 350 \\
2 \cdot 003 \\
2 \cdot 317 \\
2 \cdot 283\end{array}$ & $\begin{array}{l}0.101 \\
0.181 \\
0.364 \\
0.646 \\
1.021 \\
1.717 \\
2.555 \\
3.315 \\
3.764\end{array}$ & $\begin{array}{l}0.113 \\
0.169 \\
0.354 \\
0.636 \\
0.970 \\
1.763 \\
2.926 \\
3.926 \\
4.810\end{array}$ & $\begin{array}{l}0.097 \\
0.158 \\
0.349 \\
0.533 \\
0.748 \\
1.400 \\
2.624 \\
3.878 \\
4.995\end{array}$ & $\begin{array}{l}0.086 \\
0.133 \\
0.276 \\
0.464 \\
0.631 \\
1.085 \\
2.069 \\
3.332 \\
4.494\end{array}$ & $\begin{array}{l}0.050 \\
0.094 \\
0.189 \\
0.324 \\
0.385 \\
0.765 \\
1.416 \\
2.258 \\
3.465\end{array}$ & $\begin{array}{l}0.031 \\
0.029 \\
0.167 \\
0.176 \\
0.248 \\
0.471 \\
0.901 \\
1.427 \\
2.090\end{array}$ \\
\hline
\end{tabular}

Data derived from Case and Pearson (1957) and Registrar General (1965) 
(1953), Cutler and Loveland (1954), and Smith (1963).

In a long period of unchanging rates there will, of course, be no difference between the 'cohort' and 'time' age distributions of mortality; if the rows of a table are all the same, then the diagonals also show the same pattern. It is only during periods of changing rates that there can be any divergence between the two patterns; the theoretical background has been discussed previously in relation to tuberculosis mortality (Springett, 1950b).

Figure 2 shows the age distribution of mortality from carcinoma of the lung in alternate quinquennia from 1921-25 to 1951-55 and in the year 1963 , i.e., based on alternate rows of Table I. Figure 3 shows the age distribution of mortality for alternate five-year cohorts, using alternate diagonals of Table I. These two Figures are therefore based on the same data and differ only in

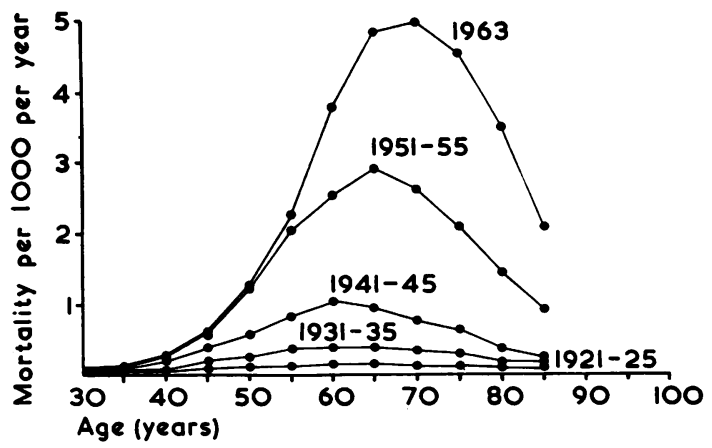

FIG. 2. Age distribution of mortality rates from carcinoma of the lung in alternate quinquennia, 1921-25 to 1951-55 and in 1963 for males in England and Wales.

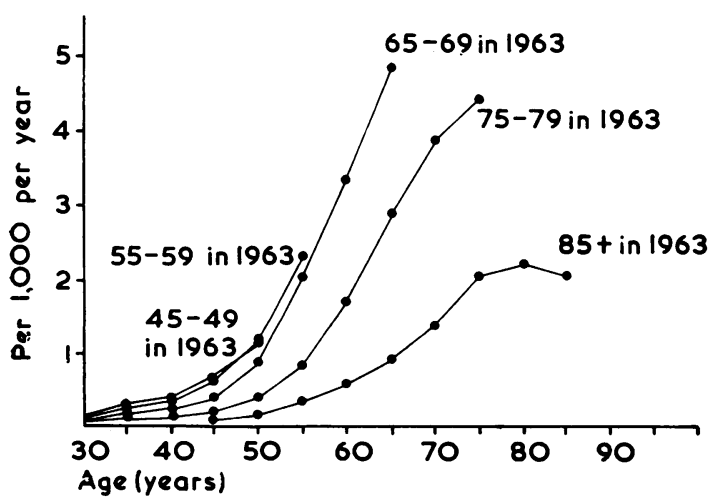

FIG. 3. Age distribution of mortality rates from carcinoma of the lung in alternate five-year cohorts of males, England and Wales. the way in which the plotted points have been joined up. The peaked time curves of Fig. 2 are to be contrasted with the steadily rising curves for cohorts shown in Fig. 3.

\section{RECENT CHANGES IN MORTALITY FROM CARCINOMA OF THE LUNG IN MALES}

The increase in mortality has recently slowed up or ceased in the younger age-groups of males in England and Wales subject to any appreciable mortality from carcinoma of the lung (Registrar General, 1953, 1959 ; Bignall, 1958 ; Ministry of Health, 1963 ; Smith, 1963). This can be seen in Fig. 2 by the superimposition of the curves for 1951-55 and 1963 at ages up to 50-54 years, and in Fig. 3 by the superimposition of the curves for the more recently born cohorts in the younger age-groups. In Table $I$ it is shown by the constancy of the rates for the younger age-groups since about 1950.

It is possible to study this slowing or cessation of increase in rather more detail by plotting the data of Table I in yet another way, viz., vertically down the columns: by doing this, the changing mortality experienced in successive periods of time by a given age-group is obtained, and is demonstrated in Fig. 4 for five-year age-groups from 40-44 years to 60-64 years during the period $1926-30$ to 1963.

Since the middle 1940s there has been no increase in rate for the age-group 40-44 years and, from the late 1940s, no increase for the next older age-group, 45-49 years. From the early 1950s there is no increase for the age-group 50-54 years, and for the five-year interval from 1956-60 up to 1963 there is no increase in mortality for the 55-59 years age-group. The broken line on Fig. 4 represents the cohort or group of people who have been the last to experience any substantial increase in mortality from carcinoma of the lung, that is, the group born in the first few years of this century.

It appears that the steady increase of carcinoma of the lung is not only coming to an end but coming to an end in this highly specialized manner of extinction in the cohort born in the early years of this century. This was indeed forecast by Korteweg (1951) when he wrote: 'If, at this moment, the increase of lung cancer in the younger age-groups came to a halt, even then it would progress in the older age-groups up till the moment when the illusionary age curve changed into the real one.' (The use of the term 'illusionary' in relation to the cohort curve is not accepted by the present writer.) 


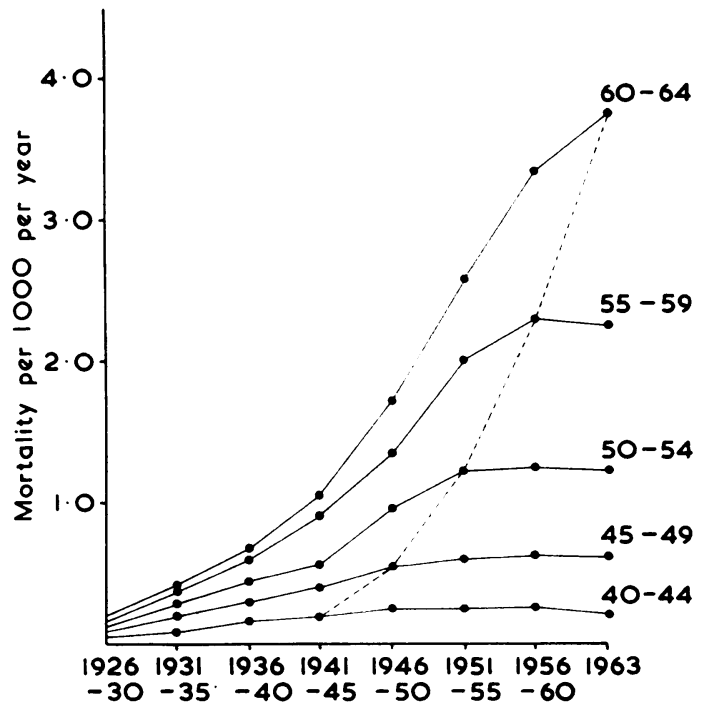

FIG. 4. Changes in mortality rates from carcinoma of the lung for selected five-year age-groups between 1926-30 and 1963: males, England and Wales.

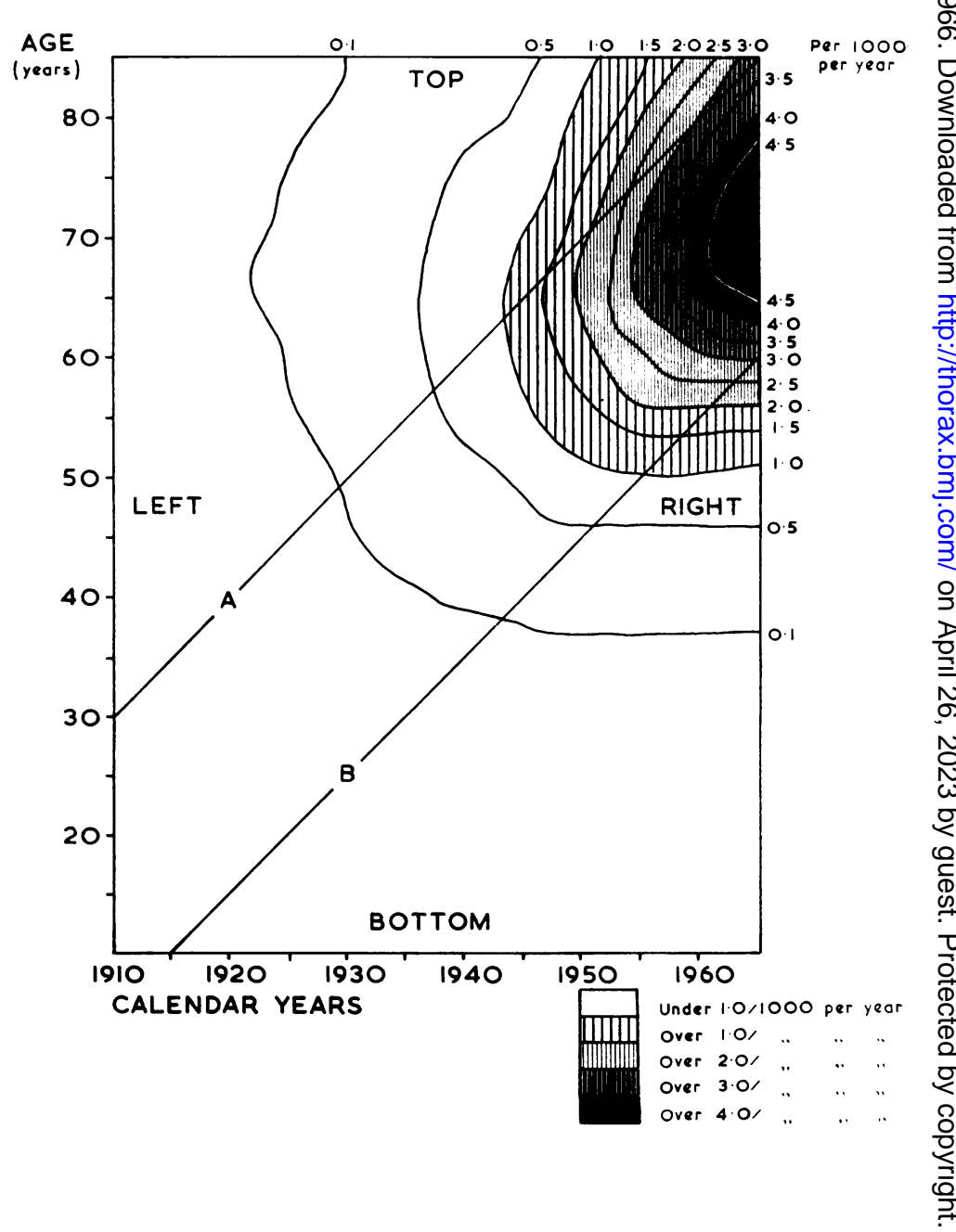

FIG. 5. 'Contour map' to show the changing age distribution of mortality from carcinoma of the lung among males in England and Wales between 1910 and 1965. Contour lines, representing levels of mortality, are drawn at intervals of 0.5 per 1,000 per year with the additional low level contour of $0 \cdot 1$ per 1,000 per year. 
Figure 5 is a method ${ }^{1}$ of combining the features of Figs 2, 3, and 4 in a single presentation; it takes the form of a contour map, the 'heights' representing mortality rates from carcinoma of the lung: the areas of greatest mortality are shown by the darkest cross-hatching. The area of the map covers ages from 10 to 85 years (measured from bottom to top) and the time period 1910 to 1965 (measured from left to right).

The low-lying area along the left-hand side of the map represents the extremely low rates, less than 0.1 per thousand per year, experienced by all age-groups before 1920 . The low-lying area across the bottom of the map represents the similarly low rates experienced by age-groups below 35 years throughout the period from 1910 to 1965 . The gradient up to the highest point (almost 5.0 per thousand per year) near the top of the right-hand side shows the increase of mortality from carcinoma of the lung from the low levels at the beginning of the century and from young ages. Where the contour lines tend to come closer together, the slope of the hill $(=$ the rate of increase) is steeper.

The age distribution of mortality at any time between 1910 and 1965 can be followed along a path going straight up the map from bottom to top; throughout the period of increasing rates, especially after 1935, it can be appreciated that this path first rises up one side of a spur and then descends on the other (as was shown in Fig. 2).

The age distributions of mortality of cohorts (illustrated in Fig. 3) are shown by paths running diagonally from bottom left to top right. Line A represents the cohorts born in 1880 ; they experienced rates less than 0.1 per thousand per year almost up to age 50 years just before 1930 ; their rates then rose with increasing steepness to reach a rate of 3.0 per thousand per year at about 80 years of age in 1960. Diagonal B represents the experience of those born in 1905 ; their mortality crossed the $0 \cdot 1$ per thousand contour under the age of 40 years in the early 1940s, and crossed all higher contours at a younger age than earlierborn cohorts: but later-born cohorts have not continued this trend, since the contour lines have swung round to become parallel with the bottom of the map below and to the right of diagonal $B$.

Finally, the paths representing the changes in time for age-groups may be followed by paths horizontally across the map from left to right. For the older age-groups at the top of the map, it is apparent that these paths are still rising, but for ages under 60 years, below diagonal B,

\footnotetext{
1Suggested by $M$. W. Springett
}

these paths have levelled off at progressively greater ages (as was shown in Fig. 5).

The curving of the contour lines below 3.0 or 3.5 , from being approximately parallel with the sides of the map to becoming roughly parallel with the bottom of the map after 1960 , suggests that, as it becomes possible to extend this diagram into the future on the right, the high point towards the top of the right-hand side is likely to be the spur at the beginning of a ridge developing at an even higher level. If no other influence comes to operate, the ridge is likely to level off at a substantially greater height than anything yet reached, but which can be reasonably projected from the rates for the cohort now aged about 60 years. If this is done, and allowing for the probable changes in age distribution of the population, the annual number of deaths from carcinoma of the lung in males in England and Wales may be expected to level off at about 35,000 to 40,000 in the 1980s. Clemmesen et al. (1953) suggested that similar changes were beginning to be apparent in the figures for Copenhagen and suggested that a final constant level of about 1,000 deaths from carcinoma of the lung for that city was likely to be reached in the late 1980 s.

EFFECT ON PROPORTION OF DEATHS OCCURRING AT DIFFERENT AGES

The continuing increase of mortality in older agegroups with constant rates at younger age-groups, coupled with the increasing proportion of older persons in the population, has led to substantial changes in the proportion of deaths from carcinoma of the lung oscurring at various age periods. The changes between 1946 and 1963 are illustrated in Fig. 6 ; the width of the columns represents the number of deaths in each year, three times as many in 1963 as in 1946. There has, however, been no increase in the number of deaths under age 45 years, so that the proportion of the total occurring at this age has fallen from $9 \%$ to $3 \%$. At age 45-54 years the number of deaths increased, but by substantially less than a factor of three, so that the proportion of deaths has fallen from $24 \%$ to $13 \%$. At age $55-64$ years, the number of deaths remains at $37 \%$. For ages over 64 years, the increase in the number of deaths has been substantially more than threefold, so that the proportion of deaths occurring at age $65-74$ years increased from $24 \%$ to $34 \%$, and over that age the increase was from $6 \%$ to $13 \%$.

Such large changes over a 17-year period suggest a need for caution in studying clinical series collected over a substantial period of time, 


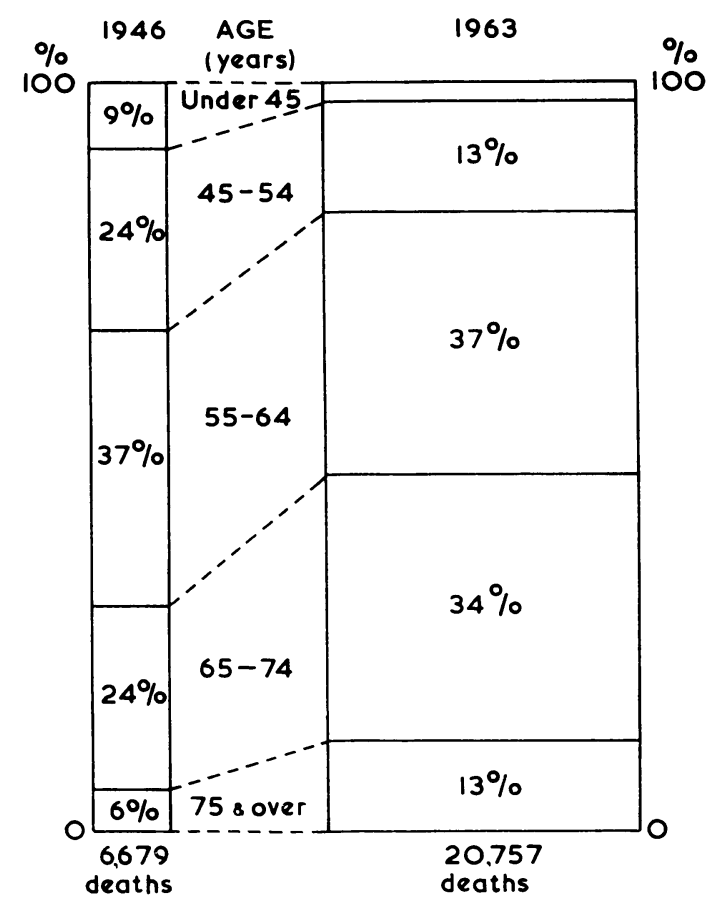

FIG. 6. Changes in age distribution of mortality from carcinoma of the lung between 1946 and 1963 in males, England and Wales.

say 10 years. If the series is a representative one, then it may reasonably be expected that the age distribution of cases in the last years of the survey may differ appreciably from that in the early years of the survey, and this could conceivably be of practical importance, for example, in assessing the response to treatment.

\section{MORTALITY FROM CARCINOMA OF LUNG IN FEMALES}

The mortality from carcinoma of the lung is at a much lower level in females than in males, but the rates in females have been increasing for many years, though for a lesser period than in males. During the period of increasing rates from 1931 onwards, there has been in each quinquennium a maximum rate of mortality at age $65-69$ or 70-74 years until 1946-50; during the 1950 s, the maxi- कs mum rate occurred at age 75-79 years and again $\overrightarrow{0}$ in 1963. Throughout this period the rates for cohorts show a steady increase with age (Table II).

So far the rates for females show a general similarity to the rates for males, with a later start to the increase which has as yet reached only a comparatively low level. Further study of the ? columns of Table II shows that there is little, if any,

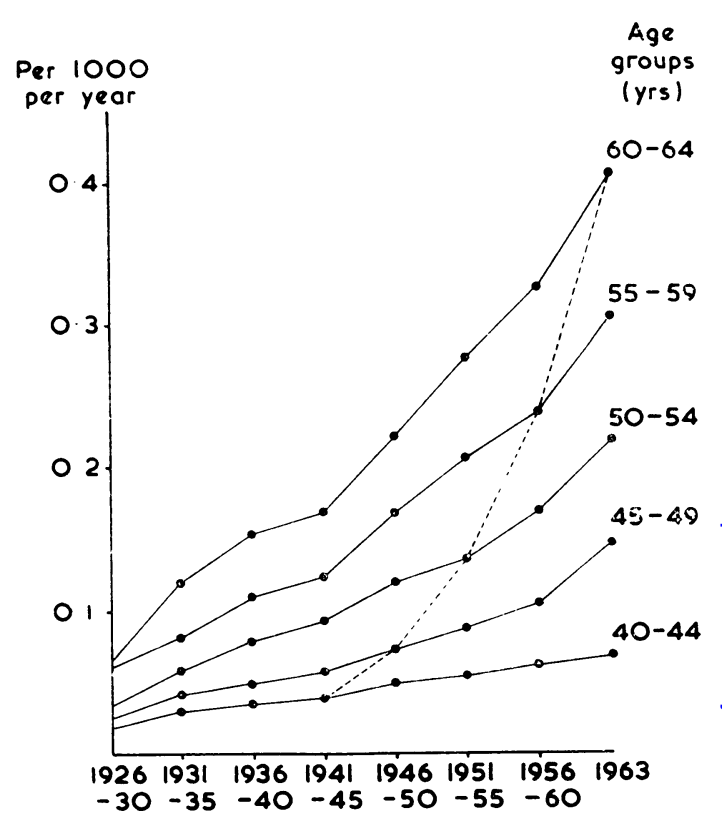

FIG. 7. Changes in mortality rates from carcinoma of the lung for selected five-year age-groups between 1926-30 to 을. 1956-60 and the year 1963 in females, England and Wales.

T A B LE I I MORTALITY RATES PER 1,000 FEMALES PER YEAR FROM CANCER OF THE LUNG AND PLEURA IN FIVE-YEAR AGE-

\begin{tabular}{|c|c|c|c|c|c|c|c|c|c|c|c|c|}
\hline & \multicolumn{12}{|c|}{ Age (yrs.) } \\
\hline & $30-$ & $35-$ & $40-$ & $45-$ & $50-$ & $55-$ & $60-$ & $65-$ & $70-$ & $75-$ & $80-$ & $85+$ \\
\hline $\begin{array}{l}1921-25 \\
1926-30 \\
1931-35 \\
1936-40 \\
1941-45 \\
1946-50 \\
1951-55 \\
1956-60 \\
1963\end{array}$ & $\begin{array}{l}0.003 \\
0.003 \\
0.007 \\
0.008 \\
0.011 \\
0.012 \\
0.015 \\
0.014 \\
0.008\end{array}$ & $\begin{array}{l}0.004 \\
0.009 \\
0.013 \\
0.016 \\
0.022 \\
0.024 \\
0.027 \\
0.031 \\
0.027\end{array}$ & $\begin{array}{l}0.012 \\
0.016 \\
0.025 \\
0.032 \\
0.036 \\
0.048 \\
0.051 \\
0.060 \\
0.064\end{array}$ & $\begin{array}{l}0.021 \\
0.023 \\
0.041 \\
0.049 \\
0.057 \\
0.073 \\
0.087 \\
0.103 \\
0.148\end{array}$ & $\begin{array}{l}0.026 \\
0.032 \\
0.055 \\
0.078 \\
0.093 \\
0.117 \\
0.137 \\
0.169 \\
0.217\end{array}$ & $\begin{array}{l}0.034 \\
0.058 \\
0.078 \\
0.107 \\
0.124 \\
0.169 \\
0.203 \\
0.240 \\
0.304\end{array}$ & $\begin{array}{l}0.050 \\
0.061 \\
0 \cdot 118 \\
0.153 \\
0.170 \\
0 \cdot 221 \\
0.281 \\
0 \cdot 328 \\
0.408\end{array}$ & $\begin{array}{l}0.050 \\
0.069 \\
0 \cdot 132 \\
0.179 \\
0.201 \\
0 \cdot 302 \\
0.349 \\
0 \cdot 380 \\
0.514\end{array}$ & $\begin{array}{l}0.050 \\
0.074 \\
0.117 \\
0.192 \\
0.226 \\
0.316 \\
0.383 \\
1.445 \\
0.552\end{array}$ & $\begin{array}{l}0.039 \\
0.073 \\
0.121 \\
0.184 \\
0.205 \\
0.309 \\
0.425 \\
0.488 \\
0.583\end{array}$ & $\begin{array}{l}0.029 \\
0.049 \\
0.095 \\
0.152 \\
0.172 \\
0.280 \\
0.391 \\
0.451 \\
0.486\end{array}$ & $\begin{array}{l}0 \cdot c 63 \\
0 \cdot 040 \\
0 \cdot 066 \\
0 \cdot 090 \\
0 \cdot 143 \\
0 \cdot 196 \\
0 \cdot 307 \\
0 \cdot 392 \\
0 \cdot 560\end{array}$ \\
\hline
\end{tabular}


evidence of any check to the increase in rates for the younger age-groups in recent periods of time: the changes are shown graphically in Fig. 7 for the same age-groups as are shown for males in Fig. 4, but with the vertical scale altered by a factor of 10 . The rates are continuing to increase at all ages.

\section{DISCUSSION}

These observations on the changing age distribution of mortality from carcinoma of the lung clearly need to be considered in relation to the reasons for the increasing mortality from this condition. They are unlikely to afford in themselves any direct explanation of the increase, but any reason advanced to explain the increase should also be capable of explaining adequately the changes in age distribution in mortality and the differing behaviour of the mortality rates in males and females.

It is difficult to see how any general environmental factor, such as atmospheric pollution or diesel fumes, could show such marked differences between males and females both in the time of onset of the increase of mortality and now of the cessation of the increase in males but not in females. Similarly, it is difficult to envisage any genetic factor which would account for a later onset of the increase in mortality in females than in males, with a persistence of the increase in females after it had ceased in males. There is, however, adequate evidence of differences between males and females in adopting the smoking of cigarettes, and these differences are now studied in more detail.

The facts concerning the history of cigarette smoking are shown in Fig. 8, based on figures from Todd (1962). For males, cigarette smoking began about 1890 and increased steadily to a maximum at the time of the second world war, after which the consumption per head fell back to pre-war levels and has since increased at a much slower rate than previously. It seems quite possible that the group of men who were adolescents or young adults at the time of the first world war were the first to be maximally exposed to cigarette smoking throughout their lives-'maximally exposed' in the sense that groups of men born subsequently did not smoke to any greater extent than the cohort who were adolescents or young adults during the first world war, i.e., those born in the first few years of the century and shown in the earlier part of this paper to be the group with whom the increase in mortality is coming to an end.

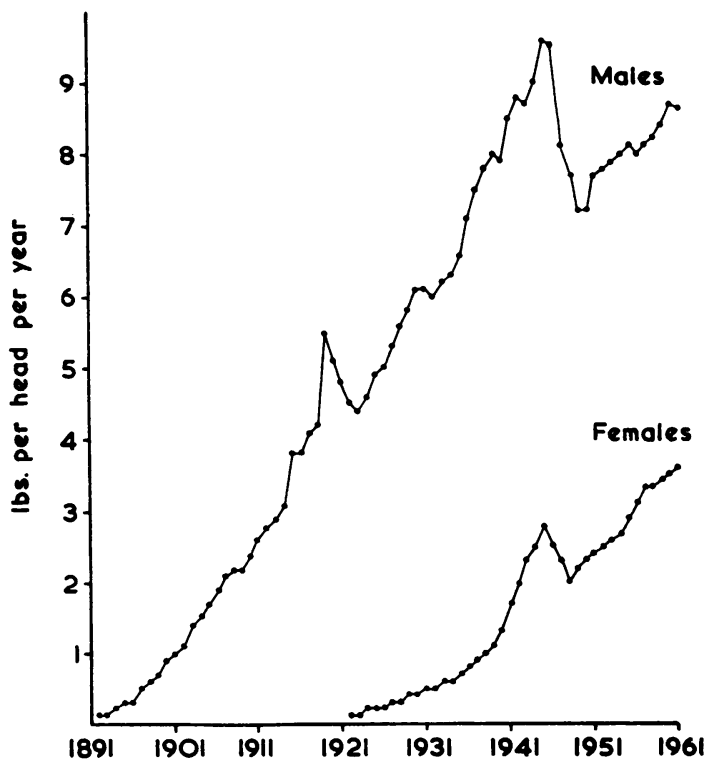

FIG. 8. Consumption of tobacco as manufactured cigarettes in Great Britain.

It is important here to distinguish between the end of an increase and a decline: there is no adequate evidence of a decline in rates in any group, only of a stabilization of the mortality rate at the new high level being established in successive age-groups by the cohort born in the early years of the century, and now aged 60-64 years; all this fits well with the cigarette consumption of males shown in Fig. 8.

In females, on the other hand, cigarette smoking did not start on any scale until 1921, but, after a small setback after the second world war, the consumption in females is now continuing to increase at approximately the pre-war rate, and this again is reflected in the steady increase in deaths from carcinoma of the lung in all age-groups of females associated with a steady rise in consumption in successive cohorts.

\section{SUMMARY}

In any recent quinquennium, the age distribution of mortality from carcinoma of the lung in males shows a maximum at age $60-64,65-69$, or $70-74$ years, and in this it differs from carcinoma of other sites, for which mortality increases with age at least up to age 80 years.

If the age distribution of mortality from carcinoma of the lung is studied in cohorts of males, 
i.e., groups of individuals followed throughout their lives, then it is found that the mortality increases with age up to 80 years.

The increase in mortality from carcinoma of the lung ceased after 1945 for the age-group 40-45 years, after 1950 for the age-group 45-49 years, after 1955 for the age-group 50-54 years, and after 1960 for the age-group 55-59 years.

The latter observation can be put in the form that the increase in mortality from carcinoma of the lung is ending with the cohort born in the early years of this century and now aged 60-64 years.

Mortality rates from carcinoma of the lung in women are at a much lower level than in men, but they continue to increase in all age-groups.

These results are compatible with a relation between smoking and carcinoma of the lung, since the group of men born in the early years of the century are likely to be the first group to have been fully exposed to the current pattern of cigarette smoking throughout their lives to date. Cigarette consumption in men is now increasing much more slowly than before the war, but it continues to increase in women.

\section{REFERENCES}

Bignall, J. R. (1958). Carcinoma of the Lung, p. 19. Livingstone, Edinburgh.
Case, R. A. M. (1956a), Cohort analysis of mortality rates as an historical or narrative technique. Brit. J. prev. soc. Med., 10, 159 . (1956b). Cohort analysis of cancer mortality in England and Wales, 1911-1954, by site and sex. Ibid., 10, 172.

— and Pearson, J. T. (1957). Tables for comparative composite cohort analysis : cancer. Appendix to Cancer Stat istics for England and Wales, 1901-1953. Studies on Medical and Population Subjects, No. 13, p. 33. H.M.S.O., London.

Clemmesen, J., Nielsen, A., and Jensen, E. (1953). Mortality and incidence of cancer of the lung in Denmark and some other countries. Acta Un. int. Canc., 9, 603.

Cutler, S. J., and Loveland, D. B. (1954). The risk of developing lung cancer and its relationship to smoking. J. nat. Cancer Inst., 15, 201.

Dorn, H. F. (1953). Morbidity and mortality from cancer of the lung in the United States. Acta Un. int. Canc., 9, 552.

Korteweg, R. (1951). The age curve in lung cancer. Brit.J. Cancer, 5 , 21.

(1953). Some remarks on the age curve in lung cancer. Acta Un. int. Canc., 9, 529.

Levin, M. L. (1953). The occurrence of lung cancer in man. Ibid., 9 , 531.

Ministry of Health (1963). On the State of the Public Health: Annual Report of the Chief Medical Officer of the Ministry of Health, 1962 , p. 97. H.M.S.O., London.

Registrar General for England and Wales (1953). Statistical Review of England and Wales for the two years 1948-49. Text, Medical, p. 158. H.M.S.O., London.

-(1959). Statistical Review of England and Wales for the year 1957. Part III ; Commentary, p. 124. H.M.S.O., London.

- (1965). Statistical Review of England and Wales for the year 1963. Part I, Tables, Medical. H.M.S.O., London.

Smith, A. (1963). Supplement: Trends in Mortality from Respiratory Disease, 1929-1963. In Annual Report of the Registrar-General for Scotland, 1963, No. 109, p. 63.

Springett, V. H. (1950a). Mortality from cancer of the respiratory tract in Norway and England and Wales. T. norske laege foren., $70,225$.

- $(1950 \mathrm{~b})$. A comparative study of tuberculosis mortality rates. J. Hyg. (Lond.), 48, 361.

Todd, G. F. (1962). Statistics of Smoking in the United Kingdom. Tobacco Manufacturers' Standing Committee Research Papers, No. 1,3 rd ed. 